\title{
Uma nova espécie do gênero Potnia Stål (Hemiptera, Auchenorrhyncha, Membracidae)
}

\author{
Gabriel Simões de Andrade
}

Centro de Ciências Biológicas e da Saúde, Universidade Estadual do Oeste do Paraná. Rua Universitária 2069, Caixa Postal 711, 85819-110 Cascavel, Paraná, Brasil. E-mail: gsa@certto.com.br

\begin{abstract}
A new species of the genus Potnia Stäl (Hemiptera, Auchenorrhyncha, Membracidae). Potnia spatulata sp. nov., from Amazonas State, Brazil, is described and illustrated.
\end{abstract}

KEY WORDS. Hoplophorionini, Membracinae, Membracoidea, taxonomy.

O gênero Potnia Stål, 1866 foi descrito para acomodar duas espécies. O montante do conhecimento dos táxons no século seguinte é sumarizado em Metcalf \& Wade (1965), onde 10 espécies são reconhecidas como válidas. Creão-Duarte \& SAKAKIBARA (1996) revisaram o gênero, reconhecendo 15 espécies válidas, das quais seis descritas como novas, e mais duas não reconhecidas. O catálogo de McKamey (1998) segue o arranjo de Metcalf \& Wade (1965), mais os apontamentos de McKamey \& Deitz (1991), perfazendo o total de 13 espécies válidas, mas por ser contemporâneo omite as novidades de CREão-DUARTE \& SAKAKIBARA (1996). Neste artigo é acrescentada mais uma nova espécie, procedente da Hiléia Amazônica, semelhante à ilustração original da fêmea de $P$. affinis Buckton, 1903. Consultando informações, S.H. McKamey (comunicação pessoal) comunicou: "It looks nothing like Potnia affinis. What you have there is a new species.".

\section{Potnia spatulata sp. nov.} Figs 1-2

Tipos e localidade-tipo. Holótipo macho de "BRASIL: Amazonas/BR 319, km. 275/17-V-1978 / Norman D. Penny", "Potnia sp./A.M. Sakakibara 1990" (depositado na coleção do Instituto Nacional de Pesquisas da Amazônia, Manaus, Amazonas, Brasil). Parátipo: 1 fêmea, "COLEÇÃO/CAMPOS SEABRA", "Obidos - Pará/BRASIL/X.1962/J. Brasilino" (depositado na coleção de Entomologia "Pe. J.S. Moure" do Departamento de Zoologia da Universidade Federal do Paraná, Curitiba, Paraná, Brasil).

Medidas (em milímetros). Macho (holótipo)/fêmea (parátipo). Largura da cabeça: 2,95/3,05; comprimento da cabeça: 0,95/1,00; distância entre os ângulos umerais: 4,80/4,80; comprimento do pronoto: 11,10/13,20; comprimento da base da cabeça ao ápice das tégminas: 9,00/9,70.

Descrição. Holótipo macho. Corpo revestido de pilosidade grísea, coloração geral acastanhada, enegrecida ao longo da sutura coronal, entre os olhos e ocelos, no contorno das impressões musculares do metopídio, nos ângulos umerais, na frente e laterais da base do processo pronotal anterior, nos bordos e superfícies intercarenas do processo pronotal anterior e na região dorso mediana do pronoto. Carenas do processo pronotal anterior e do dorso do pronoto ambarinas, algo escurecidas em intervalos irregulares. Tégminas transparentes, exceto bordo costal acastanhado e mácula amarela junto à base das veias $\mathrm{R}$ e $\mathrm{M}$; asas posteriores hialinas, com veias castanhas. Região esternal e coxas castanhas, pernas amarelo escuras.

Cabeça transversa, aproximadamente três vezes mais larga que longa, arqueada na margem superior, estriada na base em direção aos espaços ocelo-oculares, depressa ao longo da sutura coronal e dos espaços ocelo-oculares e protuberante nas áreas ocelares. Ocelos equidistantes entre si e dos olhos, situados logo acima da linha imaginária que passa pelo centro dos olhos. Lóbulos supra-antenais escavados, corrugados, com margens arrredondadas. Frontoclípeo subpentagonal, metade distal achatada ventralmente e com projeções laterais delimitadas por sulco.

Pronoto grosseiramente pontuado e corrugado, ligeiramente giboso no meio atrás dos ângulos umerais, com carenas anastomosadas no metopídio e regiões acima dos ângulos umerais, delineadas e retas na porção posterior. Lóbulos pósoculares pontuados e corrugados, com bordo posterior emarginado. Ângulos umerais aproximadamente em ângulo reto em vista dorsal. Processo pronotal anterior laminado, em forma de espátula, arredondado no ápice, com cinco carenas delineadas e paralelas entre si, porém divergentes próximo ao ápice. Processo pronotal posterior tectiforme, ápice atingindo o ângulo externo da terceira célula apical das tégminas.

Tégminas coriáceas na região adjacente à área basal da célula $\mathrm{R}$ e da célula anal, com duas células discoidais e cinco células apicais. Asas posteriores com quatro células apicais.

Pernas com tíbias clavadas, com tarsos I e II cerca de $2 / 3$ do comprimento da tíbia, tarsos III reduzidos.

Revista Brasileira de Zoologia 20 (4): 709-710, dezembro 2003 

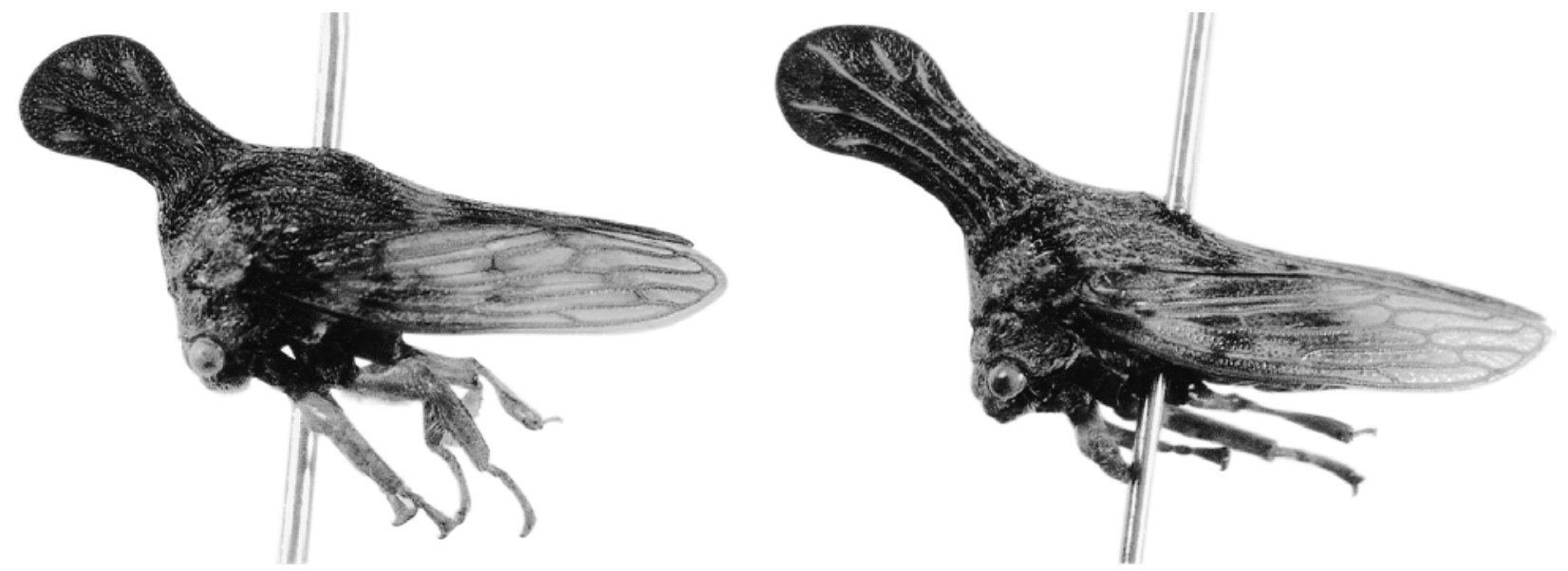

Figuras 1-2. Potnia spatulata sp. nov.: (1) holótipo macho, vista lateral esquerda; (2) parátipo fêmea, vista lateral direita (imagem invertida).

Genitália. Edeago com formato aproximado de um U, apódema alargado, armação posterior ereta, intumescida, escavada e com carenas laterais ao longo dos $2 / 4$ medianos da face dorsal, e com denticulação homogênea no terço distal da face dorsal. Parâmeros engrossados medianamente, porção apical mais esclerotinizada, dirigida para os lados e com os ápices recurvados para frente. Placas laterais do pigóforo distintas, oblongas. Placa subgenital alongada, largamente fendida medianamente.

Fêmea. Semelhante ao macho, apenas maior, notadamente o processo pronotal anterior mais desenvolvido.

Comentários. Difere das demais espécies notadamente pela conformação espatulada do processo pronotal anterior.

\section{AGRADECIMENTOS}

Ao Prof. Dr. Vladimir Pavan Margarido (Universidade Estadual do Oeste do Paraná), pela confecção dos originais das fotografias, ao Dr. Stuart H. McKamey (National Museum of Natural History, Washington, D.C.), por informações e sugestões, e aos curadores pelo empréstimo de material para estudo.

\section{REFERÊNCIAS BIBLIOGRÁFICAS}

Creão-Duarte, A.J. \& A.M. Sakakibara. 1996. Revisão do gênero Potnia Stål (Homoptera, Membracidae, Membracinae, Hoplophorionini). Revista Brasileira de Zoologia, Curitiba, 13 (4): 1001-1021.

McKamey, S.H. \& L.L. Deitz. 1991. Nomenclatural changes in the treehopper tribes Hoplophorionini, Smiliini, and Talipedini (Homoptera: Membracidae). Proceedings of the Entomological Society of Washington, Washington, 93 (1): 193-196.

McKamey, S.H. 1998. Taxonomic Catalogue of the Membracoidea (Exclusive of Leafhoppers) - Second Supplement to Fascicle 1 - Membracidae of the General Catalogue of the Hemiptera. Memoirs of the American Entomological Institute, Gainesville, 60: 1-377.

Metcalf, Z.P. \& V. Wade. 1965. General catalogue of the Homoptera. A supplement to Fascicle I - Membracidae of the General catalogue of Hemiptera. Membracoidea. In two sections. Raleigh, North Carolina State University, 1552p.

Recebido em 02.VII.2003; aceito em 15.XI.2003. 